\title{
Os modelos culturais e a crise da educação: caminhos pedagógicos na Comunicologia de Vilém Flusser
}

\author{
Diogo Andrade Bornhausen \\ Doutor; Faculdade Armando Alvares Penteado, São Paulo, SP, Brasil. \\ diogobornhausen@gmail.com
}

\begin{abstract}
Resumo
O propósito deste estudo é investigar a Comunicologia proposta por Vilém Flusser por meio de seu diagnóstico sobre as transformações éticas, estéticas e epistemológicas impostas às sociedades. Esta interrogação parte da compreensão do autor de que os modelos culturais passam por uma crise, cujo centro está na incerteza sobre a consolidação dos comportamentos, das vivências e dos conhecimentos, especialmente observados nas estruturas educacionais. Tema pouco explorado do pensamento flusseriano, a educação é compreendida como comunicação ideologicamente planejada para o funcionamento social e defendida como possibilidade de construção de novos saberes, mais conscientes e engajados diante dos cenários observados pelo autor. Com o objetivo de realizar a análise desta proposição pedagógica, esta pesquisa realiza levantamento bibliográfico destes temas, postos em diálogo com as demais reflexões de Flusser. Esta contextualização auxilia na contribuição do autor em elucidar a profunda contradição que cerca a formação do conhecimento neste início de século XXI, interposto pela intensificação de dispositivos que prometem o livre acesso global em um ambiente que incita a revisão emergente das estruturas de aprendizado.
\end{abstract}

\section{Palavras-chave}

Vilém Flusser. Comunicologia. Cultura e Educação.

Toda revolução paralisa a capacidade imaginativa dos que a sofrem. Devemos redescobrir aquilo que o mundo aponta, visa, representa e substitui, e devemos redescobri-lo não modernamente, isto é, humanisticamente, mas vivencialmente.

Vilém Flusser 


\section{Comunicologia e os modelos culturais}

Vilém Flusser (1920-1991) pertence ao grupo de pensadores que estimula interesse pela diversidade de campos do pensamento em que atuou, elaborando cenários que antecipavam questões que hoje são mais compreendidas que em sua época. Dedicado ao debate sobre os dilemas que cercam o humano, o filósofo tcheco naturalizado brasileiro procurou sempre travar intensas reflexões sobre as diversas transformações sociais, culturais e cognitivas pelas quais passam as sociedades. Seu olhar atento e provocativo direcionou-se a uma grande variedade de temas, que compõem uma extensa obra produzida em mais de quarenta anos de intensa atividade e intercâmbio com diversas áreas do conhecimento. Ainda que sua notoriedade internacional tenha vindo centrada sobre a ascensão das tecnologias e os desafios por elas impostos, a complexidade de seu pensamento esteve em aliar tais elaborações com conteúdos que transitam entre a filosofia, a antropologia, a sociologia, a religião e a linguística, principalmente.

A interdependência destes saberes fez com que Flusser buscasse sintetizá-los a partir de uma concepção de teoria geral da comunicação, denominada por ele como Comunicologia. Nela sustentava que a comunicação poderia ser definida como “[...] o processo graças ao qual informações adquiridas são armazenadas, processadas e transmitidas" (FLUSSER, 2014, p. 45). Descrição a princípio simples, se não fosse a reversão feita por ele de que a comunicação não se estabelece a partir de modelos funcionalistas de transmissão, mas antes como projeto que inclui outras duas etapas: a conservação e a elaboração dos conteúdos, que só então serão emitidos. Neste sentido, incita a pensar que as dinâmicas comunicacionais estão diretamente relacionadas aos sentidos culturais, que se constituem como modelos de pensamento que regem a vida, os comportamentos e as criações sociais. Nas palavras do autor, estes modelos representam o fundamento do humano, o chão em que se pisa (FLUSSER, 2007a), regulando a maneira como vive-se o mundo, como nele o humano se engaja.

O conjunto destas ideias foram por ele explicitadas em dois momentos, que geraram postumamente os livros Kommunikologie (FLUSSER, 2007b) e Kommunikologie Weiter Denken (FLUSSER, 2009). 0 primeiro, composto por dois escritos diferentes - Umbruch der menschlichen Beziehung? e Vorlesung zur Kommunikologie -, que reúne a síntese de seu pensamento anterior a 1977, e o segundo, organizado por Siegfried Zielinski e Silvia Wagnermaier, que reúne suas falas na Universidade de Bochum, na Alemanha, em 1991, pouco antes de seu trágico falecimento de carro. Ambas as obras representam a tentativa do 
autor em condensar os principais temas desenvolvidos ao longo da vida. Por esta razão, são consideradas norteadoras para a compreensão de suas ideias e delimitadoras de duas fases de sua obra.

Suas principais diferenças estão na maneira como Flusser preocupava-se com as transformações comunicacionais e como propunha caminhos para enfrentar estes desafios. Tendo vivido até a década de 1970 no Brasil, a primeira comunicologia reflete seu pensamento inicial, centrado na comunicação como uma ciência do "espírito" (Geisteswissenschaften) ou "humanidades", fundada primordialmente sobre o caráter simbólico da existência humana. Sob este enfoque, o armazenamento, o processamento e a transmissão das informações respondem a uma tentativa contranatural do homem diante de sua finitude, sendo por isso estruturado um mundo artificial que simboliza sua busca por imortalidade.

\begin{abstract}
Considerando a comunicação humana do ponto de vista da existência (como tentativa de superação da morte por meio da companhia de outros), ou então considerando-a do ponto de vista formal (como tentativa de produzir e armazenar informações), fica parecendo que ela, entre outros aspectos, é uma tentativa de negar a natureza, na verdade tanto a 'natureza' lá fora como também a 'natureza' do homem. (FLUSSER, 2007c, p. 94).
\end{abstract}

Com forte influência da filosofia existencial de Martin Heidegger, Flusser observa que sob a tentativa de permanência, este caráter antinatural leva à criação de modelos de pensamento projetivos, fundamentais para entender as determinações culturais e como elas estão diretamente relacionadas à forma imposta pelo modelo comunicacional preponderante. Sua principal preocupação estava em entender o caráter antropológico da comunicação ante às mudanças geradas pelas transformações técnicas, em especial as trazidas pela segunda revolução industrial, que gerou a proliferação de dispositivos simulantes neuronais, em contraposição às simulações mecânicas da primeira industrialização. Esta mudança requereria um novo entendimento antropológico, cultural e existencial sobre a forma como os meios de comunicação modelavam as consciências e desafiavam a um novo modo de pensar.

Para tanto, concomitante a estas percepções, Flusser observa a necessidade de que a comunicação seja considerada não somente como disciplina ligada às ciências do espírito, qualificando e interpretando os fenômenos, como também envolvida com as ciências da natureza (Naturwissenschaften), predominantemente quantitativas e explicativas. Este movimento, que visa realocar o lugar de observação dos fenômenos, contribui também para 
vencer a dicotomia científica, simplificadora para o autor, em prol de uma análise complexa dos objetos contemporâneos.

Alvo de suas reflexões na segunda Comunicologia, obra que sinaliza as reflexões desenvolvidas no período em que retornou à Europa, este novo encaminhamento não visava anular as primeiras conclusões, mas sim levar em consideração as transformações promovidas pelo digital. Se estes meios implicam a matematização dos códigos comunicacionais, requereriam uma readequação do olhar para uma nova epistemologia que surgia, considerando a objetividade e a intersubjetividade que desafiava os sistemas simbólicos da cultura. Para tanto, pensava sua teoria da comunicação como uma teoria mais abrangente, como afirma:

A teoria da comunicação é fundamental por dois motivos. 0 primeiro é que ela trata da atual imagem do homem (Menschenbild), que substitui e eleva a antropologia. 0 segundo, pois é uma disciplina em que inúmeras disciplinas pregressas se sobrepõem, tanto por overlap, como também por fuzzy sets. Onde uma teoria da comunicação que rompe com as estruturas do pensamento e conhecimento passados, e que não se ajusta em nenhuma universidade, deve ser lecionada? Na matemática? Nas ciências do espírito? Nas ciências da natureza? Na antropologia? Na sociologia? Onde, já que ela se serve de todas estas disciplinas? Ela utiliza a matemática, a teoria da decisão, a teoria dos jogos, a neurofisiologia, a psicologia, a sociologia, a física, a química, de tudo [...] (FLUSSER, 2009¹, p. 1a05 apud HEILMAIR, 2012, p. 35, grifo do autor) ${ }^{2}$.

É importante destacar que esta interdisciplinaridade proposta por Flusser considera a integralidade do homem como ser comunicante, respeitando suas características naturais e culturais. Contudo, não desprende de sua teoria a defesa da comunicação como campo relacional, estabelecido a partir dos códigos envolvidos na relação entre o homem e o mundo. Por tal razão, é importante a diferença que traça entre código, como mediações vinculativas pelas quais as informações são armazenadas e processadas, e suportes, detentores de propósito para a intermediação desses códigos (FLUSSER, [197-?]).

Sob esta análise, ainda que dê notabilidade aos meios, o interesse de Flusser está em como os códigos atuam sobre a cultura, suas qualidades mediadoras, e como suas mudanças trazem expressivas transformações sobre a comunicação. Dentre os que observa, destaca

\footnotetext{
${ }^{1}$ FLUSSER, Vilém. Kommunikologie weiter denken. Frankfurt: Fischer Verlag, 2009. Apud Heilmair (2012).

2 No original: "Die Theorie der Kommunikation ist aus zwei Gründen grundlegend. Der eine Grund ist, sie handelt vom gegenwärtigen Menschenbild. Es ersetzt und erhölt die Anthropologie. Und zweitens, es ist eine Disziplin, in der sich zahlreiche vorangegangene Disziplinen überschneiden, sowohl als overlap, als auch als fuzzy sets. Die Theorie der Kommunikation durchbricht die vorangegangenen Denk- und Erkenntnisstrukturen, passt zum Beispiel in keine Univesität, wo soll man so etwas unterrichten? Unter Mathematik? Unter Gesteswissenschaft? Unter Naturwissenschaft? Unter Anthropologie? Unter Soziologie? Wo? Sie macht sich ja alle diese Disziplinen zu Dienste. Sie verwendet Mathematik, sie verwendet die Entscheidungstheorie, die, die Spieltheorie, die Neurophysiologie, die Psychologie, die Soziologie, die Physik, die Chemie, alles [...]" (FLUSSER, 2009, p. 1a05).
} 
três principais como determinantes para estes desenvolvimentos. 0 primeiro é denominado pré-histórico (FLUSSER, 2008), representado pelas imagens tradicionais, figurado no mundo ritualizado e mágico e marcado por um pensamento imaginativo. 0 segundo, chamado como histórico (FLUSSER, 2010, 2007d), predominantemente textual e caracterizado pelo pensamento linear e progressivo, quando a humanidade passa a pensar conceitualmente. E, por fim, o modelo de pensamento pós-histórico (FLUSSER, 2011a), representado pelas imagens técnicas, resultante da junção dos dois anteriores mas propositor de uma nova relação onde a subjetividade da criação é abstraída e responsabilizada aos aparelhos.

Para cada um desses momentos Flusser observa a existência de condicionantes sobre a forma como as sociedades viviam e pensavam suas realidades. Os códigos imagéticos, conceituais e tecnológicos funcionariam como modelos de vivência, empregando uma estética própria, de comportamento, regulando eticamente e politicamente estes grupos, e de conhecimento, fornecendo formas específicas de consciência sobre a vida (FLUSSER, 2014). Suas modelações, portanto, ganham relevo sobre os limites e as possibilidades de realização da liberdade, tema que Flusser pensou exaustivamente sob sentidos ontológicos, fenomenológicos e metafísicos, ao perguntar-se sobre o que significaria ser, estar e, principalmente, como poderia ser a realidade para cada um desses modelos.

Em seu mais famoso livro Filosofia da Caixa Preta, Flusser (2018) demonstra claramente estas ideias e o que significam estes questionamentos. Entrevê a mudança de códigos pela qual a cultura atualmente passa - do pensamento histórico ao pós-histórico -, e, utilizando o exemplo da máquina fotográfica, indica de que maneira o humano transforma-se quando o aparelho se torna o produtor de suas imagens. Em resumo, esta transformação pode ser descrita como o limiar em que o livre arbítrio é convertido em heterodeterminação, ou seja, só é possível querer o que o programa anteriormente quis que se quisesse.

\section{Do funcionário ao homo ludens}

Ao avaliar os desafios estéticos, éticos e epistemológicos ensejados na transição para o contexto pós-histórico, sustenta que sob estas diferentes instâncias a humanidade passa por uma crise, cujo centro está na dificuldade de imaginar modelos capazes de lidar com estas mudanças promovidas pelas tecnologias. Dentre os diversos acontecimentos em que 
observa este estado de incerteza está no modo como o humano lida com sua realidade, suas informações e como encontra meios para com elas lidar e as recriar.

Em uma primeira aproximação, que caracteriza a jovem comunicologia e demais obras do período, Flusser diagnostica ter o humano se transformado em um funcionário, que simplesmente funciona em função do aparelho. Em suas palavras, no glossário que acompanha o Filosofia da Caixa Preta, o funcionário é a "Pessoa que brinca com o aparelho e age em função dele [...] [e aparelho] o brinquedo que simula um tipo de pensamento" (FLUSSER, 2018, p. 15). Sob estas duas concepções, brincar e agir em função, o funcionário se relacionaria ludicamente e servilmente a um sistema cujas regras são formas específicas de pensar, que na obra se personifica no fotógrafo que cria suas imagens a partir da decisão do aparelho, da máquina fotográfica, lhe restando somente apertar o botão, brincar, e respeitar as regras contidas no programa do aparelho, que pensará por ele.

Contudo, se consideradas as influências de Flusser para a elaboração deste conceito, estes sentidos ganham maior amplitude e profundidade. Dentre elas, dois autores são fundamentais para entender sua proposição: o primeiro Franz Kafka³ (2017a, 2017b), e seus famosos funcionários Josef K. e Gregor Samsa, protagonistas das obras $O$ Processo e $A$ metamorfose, respectivamente, e a segunda Hannah Arendt ${ }^{4}$ (2017), principalmente em seus escritos sobre o julgamento de Adolf Eichmann. Nesses personagens, ainda que tivessem vidas completamente distintas, é possível destacar a estrutura mecânica, apolítica e amoral em que se inserem, agindo de acordo com o que o programa estabelece. Os três personagens de alguma forma acabam sendo triturados, automática e inumanamente pela engrenagem do aparelho, seja ele burocrático ou político.

Se colocadas lado a lado, estas três perspectivas dos funcionários passam a significar um viver, uma ação e um saber que funcionam em favor da indústria, da técnica, a serviço do poder, seja ele burocrático, totalitário ou tecnológico. 0 funcionário, bem como o conceito de imagem técnica, ganha neste sentido uma contextualização social mais abrangente e destaca que o aparelho tecnológico não pretende somente regular os gestos, mas principalmente o modo de pensar.

Em sentido amplo, estas modelações podem também ser pensadas a partir do cotidiano tecnológico, que se propõe ser sempre mais veloz e preciso sobre os conteúdos

\footnotetext{
${ }^{3}$ Assim como Flusser, Kafka nasceu em Praga e influenciou diretamente o pensamento de Vilém, tanto por suas percepções da cultura europeia, quanto por seu estilo, como pelos personagens de seus romances. Diversos textos de Flusser dedicam-se a explorar estas características, principalmente pelo modo como Kafka retrata a não humanidade e a questiona acerca dos costumes e crenças arbitrários.

${ }^{4}$ Hannah Arendt possui forte presença no pensamento de Flusser. Ambos viveram os traumas do Holocausto e ambos se preocuparam com a questão da liberdade, do acriticismo e dos efeitos dos totalitarismos. Sobre ela, Flusser ministrou o curso Hannah Arendt em 1966 na Biblioteca São Paulo, cujo manuscrito encontra-se disponível no Arquivo Vilém Flusser São Paulo.
} 
disponibilizados, empregando em seus consumidores uma enorme atração, a ponto de delegarem a eles suas próprias capacidades, cognitivas principalmente. Para Flusser (1988), isto acontece pois os aparelhos possuem estrutura complexa, são impenetráveis, não se sabe como funcionam, como seus programas operam. Por isso o comportamento diante deles, seu uso, é simples, bastando apertar os botões ou arrastar os dedos. Ainda, para o autor este uso é idiotizante, emburrecedor. 0 funcionário não pensa, ele simplesmente opera. Não há conhecimento, não há criação. Os modelos de vivência, comportamento e conhecimento possuem, portanto, maior facilidade para se irradiarem e atuarem sobre o social. Por esta razão, Flusser (2002) não denomina o funcionário como homem, já que para ele a humanidade pressupõe existência (ek-siste, ou seja, superação de algo, criação). Algo que o funcionário não tem, pois não age criativamente.

Centrado sobre as possibilidades de criação do conhecimento, que para Flusser não é uma simples informação, porque implica uma qualificação existencial do pensamento frente à realidade, esta primeira aproximação comunicológica evidencia uma reflexão severamente crítica e por vezes sem esperança sobre alternativas possíveis neste contexto comunicacional. Perspectiva que se modificará significativamente na segunda parte de sua obra, que caracteriza a comunicologia madura.

Nela não se trataria de somente destacar a crise existencial pela qual a sociedade passa pós-historicamente, ainda que tal crítica se mantenha, mas sim encontrar meios para uma nova antropologia que se considera os novos paradigmas impostos para a cultura pelos códigos digitais. Para tanto, Flusser sustenta a necessidade de um outro modo de agir, mais engajado e consciente sobre as estruturas programáticas dos aparelhos, em prol de uma ação criativa diante das informações. Exemplificando esta possibilidade, quando explica sobre a estrutura complexa do aparelho, faz uma outra relação paralela, a de estruturas simples que por serem simples possuem usos complexos, como o jogo de xadrez, fácil em relação às suas regras, ao seu funcionamento, mas desafiante cognitivamente (FLUSSER, 1988). Para ele estes usos não são dependentes de suas estruturas e que por isso se poderia, hipoteticamente, ter um uso complexo, criativo, que gere o conhecimento em estruturas complexas, como os aparelhos tecnológicos.

Sua insistência em aproximar a formação do conhecimento com a imagem do jogo, como o fez ao conceitualizar o funcionário, o aparelho e suas relações, justifica-se, pois, Flusser entende que a partir desta nova antropologia as antigas leituras sobre o homem não são mais aplicáveis. Não se estabeleceria o homem mais a partir de uma vida contemplativa (sapiens), nem ativa (faber) e também não mais econômica (laborans) (FLUSSER, 1967), pois 
não haveria mais modificação material em um cenário em que os aparelhos programam e fornecem a totalidade das informações. Restaria ao homem a inércia tediosa coordenada pelo aparelho, como indicada na leitura crítica sobre o funcionário, ou engajar-se como homo ludens, que joga e brinca contra os aparelhos, visando um saber novo.

Em suma: o que devemos aprender é assumir o absurdo, se quisermos emancipar-nos do funcionamento. A liberdade é concebível apenas enquanto jogo absurdo com aparelhos. Enquanto jogo com programas. É concebível apenas depois de termos assumido a política, e a existência humana em geral, enquanto jogo absurdo. Depende de se aprenderemos em tempo de sermos tais jogadores, se continuarmos a sermos 'homens', ou se passaremos a ser robôs: se seremos jogadores ou peças de jogo. (FLUSSER, 2011a, p. 31).

As possibilidades abertas pelo jogo ganham na Comunicologia um caráter existencial muito particular, pois implicam a remodelação dos modelos de vivência, comportamento e conhecimento em prol da liberdade de decisão sobre as designações vindas dos aparelhos. Ao enaltecer a crítica e as possíveis alternativas para o cenário promovido pelas tecnologias, contribui ao ter antevisto diversos dilemas enfrentados pela comunicação, principalmente ligados ao modo como o uso aos aparelhos é feito, suas atratividades, bem como a estrutura que os sustenta, laboratorialmente investida pelos algoritmos de regulação e filtragem de representações e simbolizações do mundo.

Contudo, ainda que Flusser tenha feito referência a esta concepção de jogo sob diferentes aspectos em sua obra, os caminhos para a concretização dessas possibilidades e ações criativas são com frequência enigmáticos e com difícil visualização de sua aplicação. Em especial nas duas obras que fazem menção direta à Comunicologia, as respostas não parecem claras e definitivas sobre estas questões, mesmo que indique razões para isto ocorrer e forneça dicas para superar. No entanto, quando considerado que a comunicologia não esteja presente somente nessas duas obras, mas que se encontra distribuída na totalidade de seus escritos, é possível localizar pontos nos quais Flusser procurou efetivamente engajar-se em alternativas à condição anteriormente apresentada. Seu incentivo a outros modos de pensar e jogar diante da realidade dada são possíveis de serem encontrados em quatro principais campos, a saber: sua teoria da tradução, a dúvida, sua concepção de arte e suas proposições educacionais.

Nestes quatro são perceptíveis suas tentativas de engajar-se pessoalmente na transformação dos modelos de pensamento dominantes. No primeiro, encontrado principalmente na obra Língua e Realidade (FLUSSER, 2007d), centra sua análise sobre a 
forma como a língua determina a percepção, a alienação e a atuação sobre o mundo e sobre as diversas experiências vividas. Influenciado pelo pensamento de Ludwig Wittgenstein, Flusser vale-se de seu poliglotismo para elucidar que a realidade poderia ser também criativamente vivida, a depender do envolvimento epistemológico de seus participantes e de suas disponibilidades ao jogo linguístico. Sob a mesma premissa reflexiva, elabora como método o "duvidar" (FLUSSER, 2011b), contraposto ao paradigma cartesiano, em que sustenta o exercício do questionamento como necessidade permanente de enfrentamento da realidade dada. Diante desse pensar, defende ainda uma ação criativa que se relacionaria ao fazer artístico, tema analisado diversamente em sua obra, especialmente em sua proposição para a Bienal de Artes de São Paulo e no intenso diálogo com dezenas de artistas. Ali explicitava o desejo em ver a expressão estética como instrumento inventivo de remodelação dos padrões nos quais a sociedade se inseria.

Amplamente divulgadas em suas diversas publicações, estas três ações vinculam-se diretamente às qualidades éticas, estéticas e epistemológicas mencionadas na comunicologia como modeladoras de comportamentos, vivências e conhecimentos. Em cada qual, Flusser buscava interrogar-se e modificar estes sentidos em prol de uma conscientização sobre os códigos atuantes. No entanto, em um conjunto de dez textos poucos conhecidos, problematiza outra face destes fenômenos, visto por ele como fundamental para a compreensão sobre o mencionado condicionamento e redução criativa diante dos conteúdos. Sustenta que a crise destes modelos reflete uma crise mais profunda, localizada na forma como os conhecimentos armazenados são culturalmente transmitidos, ou seja, centra sua análise sobre as estruturas educacionais, tanto as problematizando como vendo nelas as possíveis mudanças no tecido comunicacional das sociedades.

É interessante notar que ao pensar a educação não propõe propriamente uma teoria ou um método pedagógico, mas acentua nestes escritos justamente a crise dos saberes que percorre sua comunicologia. Como declarou em sua autobiografia, foi na trajetória como professor que desenvolveu seus principais temas e foi no ambiente educacional que percebeu os maiores desafios da passagem do pensamento histórico para o pós-histórico (FLUSSER, 2007a). A educação atualmente em curso representaria, de acordo com tal ideia, a tentativa de transmitir modelos esvaziados. Ao observar os sentidos que levaram a este esvaziamento, destaca as sequentes inversões que o modelo industrial sustentou como prática e construção dos saberes. Este modelo é o que sustenta, para o autor, a formação do funcionário e que consiste fundamentalmente na maneira como a sociedade foi e está sendo 
educada, tanto pelas instituições de ensino, mas também, por consequência, pelos meios de comunicação.

\section{A crise da educação}

Ao retomar suas compreensões sobre armazenamento, processamento e transmissão, Flusser recorre às raízes dos modelos de permanência dos sentidos culturais para elucidar a maneira como os sistemas educacionais foram tradicionalmente compreendidos. Centra sua atenção, portanto, no modelo da Paideia Ocidental, que para ele foi fundada e por muito tempo mantida em uma estrutura piramidal: (1) a vida econômica; (2) a vida política, lugar da produção de obras; e (3) a vida contemplativa, lugar de contemplação das ideais imutáveis. De acordo com tal antropologia, a economia sustenta a política e por sua vez a filosofia, onde a escola (skholé, ócio), “[...] é o estado em que uma pessoa se abre para o sagrado [...]" (FLUSSER, 1970, p. 1), sendo por isso uma meta de vida e o principal meio de formação do homem em sua cultura.

No entanto, a partir da revolução burguesa esta pirâmide passa por gradativa inversão. Flusser (1987) nota que ao assumirem o Estado, os burgueses transformaram o objetivo educacional ao prioriza-lo como sustentação de suas políticas. Neste sentido, a educação não contempla mais teoricamente, mas utiliza estas teorias com o propósito de produção de obras. 0 objetivo deste Estado não é mais a sabedoria, mas a atividade produtora. A degradação da escola do primeiro para o segundo lugar na hierarquia existencial, é consequência de reformulação do conceito teoria. "Não mais contemplação de ideias imutáveis, mas elaboração de ideias aperfeiçoáveis." (FLUSSER, 1983, p. 3). Em resumo: conhecer é mudar o mundo. Isto se evidenciaria no modo como este modelo passa a estruturar seus níveis:

Em nível primário, lugar de adestramento para a vida econômica, da vida com máquinas e seu eterno retorno. Em nível secundário, lugar de preparação para vida política, a que produz e distribui as obras. Em nível superior, lugar da elaboração das teorias e das técnicas que permitam a produção progressiva de obras [...] Em tal sentido, toda escola burguesa é 'politécnica', e é a técnica que a caracteriza. (FLUSSER, 1983, p. 4).

Sob este funcionamento, a escola burguesa busca formar agentes, isto é, o homem é homo faber. O seu ideal é a transmissão dos modelos de funcionamento por parcelas recortadas em disciplinas, achando-se pois a totalidade desses modelos disponível à cultura repartida entre vários professores e alunos. Converte-se portanto em a ascholia (negação do 
ócio, negócio), onde o ensino esvazia-se como modelo ao privilegiar o fazer utilitário em detrimento do conhecimento contemplativo (FLUSSER, 1983).

Neste sentido, a acumulação e a transmissão são privilegiadas ante ao processamento das informações, resultando em um excedente de conteúdos que ultrapassa a capacidade de assimilação de seus participantes. A compartimentação dos saberes construídos em diferentes disciplinas surge, portanto, como resposta possível à quantidade de dados armazenados. Para Flusser [198-?], esta transformação objetiva trará uma série de impactos danosos tanto a estas instituições como aos que nelas convivem. Um dos principais danos é o cerceamento do livre pensar em prol de funcionalidades específicas. 0 resultado ideal de um tal ensino é o profissional, o funcionário e o especialista, cerceado dos valores fundamentais para uma atuação complexa na realidade.

O nível superior da escola burguesa é lugar de iniciação curiosa. 0 futuro cientista e técnico é lavado catarticamente de todos os valores, suas dimensões políticas, ética e estéticas são amputadas, e apenas as estruturas da razão são conservadas. Destarte poderá ele elaborar modelos teóricos isentos de valor, aplicá-los objetivamente. 0 resultado é, de um lado, um mundo teórico vazio e inimaginável e, do outro lado, um mundo manipulado tecnicamente, de mais em mais absurdo. (FLUSSER, 1983, p. 5).

Especialmente atento às regulações que operam no Ensino Superior, lugar tradicionalmente marcado pela formação de uma elite responsável por impor modelos, Flusser nota neste ambiente o principal sintoma de derrocada da educação. Isso porque essa elite já não possui capacidade de entender e controlar as diferentes estruturas sociais, tendo se tornado obsoleta em época marcada pela ascensão tecnológica (FLUSSER, 1971). A estrutura desses meios, envolvida pelas tentativas em disponibilizar uma grande quantidade de informações simultaneamente e promove-las a partir de uma maior horizontalidade de acesso, influi diretamente sobre o campo de atuação social desta elite ao questioná-la nos fundamentos de sua autoridade. De um lado, porque diante do excedente de conteúdos, não há viabilidade humana em conseguir armazenar tamanho volume de dados, tornando a transmissão dos saberes "inoperante, superposta e redundante" (FLUSSER, 1972a, p. 2). Por outro lado, o lugar discursivo e hierárquico, personificado no professor, entra em crise, em especial porque suas emissões de ideias tornam-se inertes ao serem assimiladas e armazenadas de forma passiva pelos alunos, não atendendo diretamente ao novo posicionamento que estes receptores de informação passam a ter. 
Os aparelhos acentuam o desajuste implícito do modelo burguês em querer garantir o armazenamento e transmissão dos saberes produzidos, pois seus programas se incumbem de realizar com mais perfeição justamente estas duas operações. Como resultado, as imagens técnicas terão maior capacidade de infiltração cotidiana, facilitando a apreensão e superficializando a formação de conhecimento. Tal abismo que se abre entre o campo educacional e o cenário midiático leva ao acirramento desta crise, cujo centro está nos modelos culturais e na forma como são compreendidos. Para Flusser (1972b),

[...] a solução de tal problema exige que mudem por completo as atitudes da humanidade com relação a modelos. A crise do ensino é subcrise dos valores. Se a crise dos valores não for resolvida, o ensino passará a ser tarefa de televisões e aparelhos. (FLUSSER, 1972b, p. 1).

\section{0 ensino da comunicação}

Em resposta a estas avaliações sobre a crise dos valores, Flusser buscou alternativas viáveis para a superação destas condições, tanto em seus escritos quanto em seu engajamento prático nos diversos cursos que ministrava. Para ele, isto significaria rever as estruturas regulatórias, típicas do modelo moderno, retirando a primazia pela especialização e seu acúmulo de informações em prol de uma universalização do saber que permitiria uma nova forma de se lidar com os conteúdos.

A oportunidade que teve para realizar estas elaborações e tentar coloca-las em prática ocorreu em meados da década de 1960 em São Paulo, quando foi convidado para planejar o curso de Comunicação e Humanidades da Fundação Armando Alvares Penteado (FAAP-SP) (FLUSSER, 1966). Este curso, que se iniciara a partir da associação desta faculdade com o Instituto Brasileiro de Filosofia, visava aproveitar os diálogos filosóficos dos intelectuais associados a esta Instituição para formar um corpo discente capaz de lidar com as muitas transformações que aquela época impunha (FLUSSER, 1965). Por tal razão, as ideias de Flusser nascem do resultado de sua interlocução com Miguel Reale e Milton Vargas, a quem Flusser também substituiu na disciplina Filosofia do Conhecimento da Escola Politécnica da Universidade de São Paulo. Em comum, defenderam uma proposta pedagógica denominada inicialmente como Studium Generale, similar com o modelo renascentista do uomo universale, que visava à integralidade do conhecimento e à superação da separação entre ciência, política e arte (FLUSSER, 2007a). Este ideal de religação dos saberes teve como influência diversas reflexões que vinham sendo pensadas pelas universidades europeias no pós-guerra na tentativa de elaborar soluções alternativas para 
as questões que este período trouxe com sua racionalidade tecnológica. Foram expoentes no diagnóstico e na proposta de soluções: Ernst Cassirer, Max Bense, Arnold Gehlen e Günther Anders 5 .

A originalidade do projeto de Flusser esteve em conjugar o Studium Generale europeu com o contexto trazido pelas tecnologias da comunicação. No entanto, para ele não se tratava de replicar o modelo renascentista, mas sim aproveitar-se dos dados programados e disponibilizados pelos aparelhos para criar um conhecimento universalista que não prezasse a modelação, mas sim a estratégia. Em nova aproximação com a ideia de jogo, explica que enquanto o ensino tradicional estava ancorado na transmissão de um máximo de dados (conteúdos) e no mínimo de regras (possibilidades criativas), o novo caminho educacional defendido deveria converter-se para poucos dados e muitas regras, ou seja, transformar o saber tecnocrático em um saber engajado (FLUSSER, 1969). À Teoria da Comunicação, disciplina que Flusser pessoalmente assumiu, caberia articular novas regras, articulando uma consciência universalizada aliada a uma multiplicidade de outras disciplinas (de jogos), operando sinteticamente as várias camadas de significado de um fenômeno vivenciado.

Sua Comunicologia funcionaria como metadiscurso que englobaria complexamente outros saberes, permitindo que o conhecimento fosse construído por meio do jogo, subtraindo do filosofar o fundamento tranquilizador e se projetando ou lançando ludicamente a realidade na falta de fundamento através da constante experimentação com as regras (FLUSSER, 2007a). O ensino da comunicação significaria resgatar um conhecimento integral que superasse a separação dos valores científicos, políticos e artísticos. Para Flusser (1983), este modelo escolar conjugaria o caráter politécnico com o filosófico, permitindo "[...] que os técnicos sejam novamente artistas, os artistas técnicos, e que ambos sejam politicamente responsáveis." (FLUSSER, 1983, p. 7). Quando teoria e vivência concreta estivessem interligadas, "[...] tal escola seria lugar de sabedoria em sentido platônico, com a diferença que todos seriam reis, e as máquinas seriam os idiotas." (FLUSSER, 1983, p. 7).

Em carta a Miguel Reale, quando pensavam esta proposição, Flusser (1977) esclarece suas ideias:

\footnotetext{
5 Ernst Cassirer (2004), já em 1942, apresentou uma proposta para a ciência da cultura integrada às ciências exatas, naturais e da tecnologia. Max Bense, defendeu sua tese de doutorado em 1937, intitulada Quantenmechanik und Daseinsrelativität (Mecânica Quântica e Relatividade do Ser-aí). Arnold Gehlen (1960) contribuiu com estas discussões ao pensar sobre a nova posição do ser humano em uma natureza confrontada e imposta pela técnica, assim como de Günther Anders (2011a, 2011b) com seu estudo Die antiquierheit des menschen: über die seele im zeitalter der Zweiten Industriellen Revolution (A obsolescência do homem: sobre a alma na época da Segunda Revolução Industrial].
} 
Em suma: acredito que é possível superar a nefasta separação da arte, da política e da ciência, tão tipicamente burguesa e que resultou em arte pela arte, em política enquanto ideologia, e em ciência enquanto 'pesquisa objetiva', somente depois de ter superado a pretensa 'subjetividade da inspiração' tanto quanto a pretensa 'objetividade do conhecimento científico'. E isto é possível somente se admitirmos que toda arte tem dimensão autenticamente epistemológica, toda política tem dimensão estética e epistemológica, e que ciência é um fazer artístico e político que visa conhecer o mundo afim de torná-lo melhor e mais belo. Isto é: se admitirmos a intersubjetividade de todo fazer humano, o fato de ele estar no mundo com outros, e de estar no mundo por nele estar com outros. (FLUSSER, 1977, p. 2).

Em sentido prático, estas motivações eram buscadas por meio do incentivo aos alunos para modificarem suas atitudes diante das informações. Tarefa nem sempre exitosa, como várias vezes demonstrou com sentimento de frustração, seu objetivo foi possibilitar que seus ouvintes saíssem de um "ensimesmamento" (FLUSSER, [196-]), característico da forma como a sociedade consome informação e que gera o funcionário, para tornarem-se "disponíveis" ao jogo que ele aplicava, como comentado, por meio da linguagem, da dúvida e das artes (FLUSSER, 1989). Acreditava que a partir desta sensibilização os alunos estariam aptos a operar comunicologicamente sobre os fenômenos. Para tanto, insistia para que a educação não falasse mais "sobre", mas "com", recusando modelos estabelecidos para articular dúvidas e propondo diálogos capazes de "[...] provocar zonas de subversão intelectual [nos alunos, visando] libertar a juventude pra ser ela mesma." (FLUSSER, 2007a, p. 273). Com isso, os alunos atuariam na recusa da especialidade em favor da competência “[...]para a elaboração de informações (formas) novas.” (FLUSSER, 1983, p. 3).

As formas, as estruturas subjacentes, deixarão de ser tema, e passarão a ser estratégias inter-subjetivas. Os participantes da escola deixarão de ser programados e passarão a ser programadores dialógicos dos aparelhos. Não mais programarão programas, mas os próprios aparelhos. Viverão trans-aparelhisticamente. A sociedade totalitária virará democracia em sentido jamais imaginado anteriormente. (FLUSSER, 2011a, p. 271).

Este intento pelo engajamento e pela autonomia, que acompanhou toda sua trajetória intelectual, pretendia educar a sociedade para os novos modelos propostos pelo cenário pós-histórico, capacitando para operarem por meio da constante experimentação criativa, como indicara em sua concepção de homo ludens. Neste sentido, tal projeto seria a efetivação da nova antropologia, na qual a mudança do tecido comunicológico da sociedade depende da superação da crise por meio de um agir integral, pois, “[...] enquanto não houver 
espaço para a política, para diálogos circulares não elitários, a crise da ciência se apresenta insolúvel." (FLUSSER, 1983, p. 7).

\section{Conclusão}

Ao se considerar este conjunto de ideias sobre as condições educacionais que marcam a cultura, Vilém Flusser demonstra sua contínua preocupação em compreender os modelamentos aos quais a sociedade se sujeita, em especial a partir da presença dos meios de comunicação. Expostas diretamente em um conjunto pequeno de textos, estas concepções sobre o ensino e suas transformações demonstram perpassarem todo o conjunto de sua obra, o que colabora para entender a diversidade de leituras que a obra de Flusser suscita.

Em especial relação com as duas obras em que Flusser apresenta sua Comunicologia, suas concepções sobre o ensino colaboram na compreensão sobre sua trajetória de reflexões que marcaram as duas fases de sua obra. Tendo elaborado a maior parte destes textos quando lecionava nas universidades em São Paulo, ajudam a embasar as primeiras conclusões comunicológicas, como visto, centradas em um caráter existencial e preocupadas com os dilemas que cercam o humano após a ascensão tecnológica. Neste sentido, os modelos educacionais demonstram-se fundadores de uma comunicação ideologicamente planejada que atua para a fragmentação e funcionalização dos saberes, que culminará na formação dos funcionários, inertes e não reflexivos sobre suas atuações no mundo.

Contudo, neste mesmo projeto, estariam presentes as possibilidades criativas e transformadoras que Flusser sinaliza com mais clareza na segunda comunicologia, quando defende a necessidade de uma nova antropologia que considerasse um outro modo de lidar do homem, mais preparado e disponível para reinventar-se diante das revoluções comunicacionais em curso. Um dos fios condutores destes caminhos que apresenta em sua obra está, portanto, em como o autor enxergava os modelos de pensamento formados a partir do ensino e como neles se envolvia.

Sob este aspecto, junto dos outros campos em que Flusser engajou-se para buscar alternativas aos desígnios culturais, estas formulações apontam para um pensador que encontrou no ambiente educacional instrumentos e possibilidades para mudar o mundo, como por vezes afirmaria. Externaliza nelas os principais dilemas que o afetaram, tanto na tentativa de promoção de capacidades autônomas, como na constatação das contradições da racionalidade técnica, o que fariam angustiar-se diante das estruturas burocráticas que 
geram a especialização danosa a essa liberação. 0 ensino estaria, dentre os diversos caminhos que o autor explorou, como possibilidade efetiva de realizar seu modelo dialógico de comunicação, englobando uma consciência ética, epistemológica e estética que visava permitir à sociedade ter maior responsabilidade e abertura para saber atuar em benefício de suas transformações.

Somado a isto, jogar luz sobre estes diagnósticos contribui no esclarecimento sobre os principais desafios que cercam os modelos de educação em voga. 0 ensino ainda em curso se nutre de estruturas que não foram planejadas para considerar os cenários midiáticos como participantes e reconfiguradores dos processos de aprendizado. Como resultado, uma submissão crescente aos sistemas utilitaristas de construção de saber e uma delegação a terceiros do que será abordado e como serão valorados os conteúdos transmitidos. Flusser auxilia, portanto, na elucidação da profunda contradição que cerca a formação do conhecimento neste início de século XXI, interposto pela intensificação de dispositivos que prometem o livre acesso global em um ambiente que incita a revisão emergente das estruturas de aprendizado.

A absorção tecnológica pela qual passa a sociedade, que por vezes negligencia o poder destes aparelhos como construtores da realidade, demonstra, como Flusser anteviu, uma crise sobre a atuação dos sujeitos diante das informações, sobre os objetivos inscritos nestas formas de transmissão e sobre o lugar de elaboração destes saberes, hoje radicalmente estendidos à crescente deslegitimação das ciências por meio da desinformação. Para além de uma inserção arbitrária da tecnologia nos ambientes de aprendizado, o que Flusser contribui ao pensar sobre a natureza desses ambientes é sobre a necessidade de retomada destes como espaços de reflexão sobre o estar no mundo, repensando o lugar e o fazer neste ambiente comunicativo. Como indicado nas epígrafes, dentre as alternativas, as capacidades imaginativas e vivenciais diante destes desafiadores fenômenos talvez possibilitem a redescoberta sobre a formação do conhecimento.

\section{Referências}

ANDERS, Günther. La obsolescencia del hombre: sobre el alma en la época de la revolución industrial. Valencia: Pre-textos, 2011a. 1 v.

ANDERS, Günther. La obsolescencia del hombre: sobre la destrucción de la vida en época de la tercera revolución industrial. Valencia: Pre-textos, 2011b. 2 v.

ARENDT, Hannah. Eichmann em Jerusalem: um relato sobre a banalidade do mal. São Paulo: Companhia das Letras, 2017. 
CASSIRER, Ernst. A filosofia das formas simbólicas. Martins Fontes: São Paulo, 2004.

FLUSSER, Vilém. Filosofia da caixa preta: ensaios para uma futura filosofia da fotografia. São Paulo: É Realizações, 2018.

FLUSSER, Vilém. Comunicologia: reflexões sobre o futuro. São Paulo: Martins Fontes, 2014.

FLUSSER, Vilém. Pós-História: vinte instantâneos e um modo de usar. São Paulo:

Annablume, 2011a.

FLUSSER, Vilém. A dúvida. São Paulo: Annablume, 2011b.

FLUSSER, Vilém. A Escrita: há futuro para a escrita? São Paulo: Annablume, 2010.

FLUSSER, Vilém. Kommunikologie weiter denken. Frankfurt: Fischer Verlag, 2009.

FLUSSER, Vilém. A história do diabo. São Paulo: Annablume, 2008.

FLUSSER, Vilém. Bodenlos: uma autobiografia filosófica. São Paulo: Annablume, 2007a.

FLUSSER, Vilém. Kommunikologie. Frankfurt: Fischer, 2007b.

FLUSSER, Vilém. 0 mundo codificado: por uma filosofia do design e da comunicação. São Paulo: Cosac Naify, 2007c.

FLUSSER, Vilém. Língua e realidade. São Paulo: Annablume, 2007d.

FLUSSER, Vilém. Da religiosidade: a literatura e o senso de realidade. São Paulo: Escrituras, 2002.

FLUSSER, Vilém. Ensino Estético. [S. l.]: Arquivo Vilém Flusser São Paulo, 1989.

FLUSSER, Vilém. On writing, complexity and the technical revolutions. Interview by Miklós Peternák. Osnabrück: Universität der Künste Berlin, 1988. 1 DVD (10 min).

FLUSSER, Vilém. Escola Primária. In. 1-ANP-04_1831_ESCOLA PRIMARIA. BOOKS 27_1ANP [1826]_SUPONHAMOS. Arquivo Vilém Flusser São Paulo, 1987.

FLUSSER, Vilém. Para uma escola do futuro. [S. l.]: Arquivo Vilém Flusser São Paulo, 1983.

FLUSSER, Vilém. Pós-História e Educação. 2-PHIST-03_2002_POS-HISTORIA E EDUCACAO. 2-PHIST [1999] POS-HISTORIA [CENAFOR]. Arquivo Vilém Flusser São Paulo, [198-?].

FLUSSER, Vilém. [Correspondência]. Destinatário: Miguel Reale. [S. l.]: Arquivo Vilém Flusser São Paulo, 21 dez. 1977.

FLUSSER, Vilém. Ensino Superior. [S. l.]: Arquivo Vilém Flusser São Paulo, 1972a.

FLUSSER, Vilém. Ensino. [S. l.]: Arquivo Vilém Flusser São Paulo, 1972b. 
FLUSSER, Vilém. A questão do ensino superior. [S. l.]: Arquivo Vilém Flusser São Paulo, 1971.

FLUSSER, Vilém. Da crise da educação. [S. l.]: Arquivo Vilém Flusser São Paulo, 1970.

FLUSSER, Vilém. A perda da fé. [S. l.]: Arquivo Vilém Flusser São Paulo, [197-?].

FLUSSER, Vilém. Ensino Multivalente. [S. l.]: Arquivo Vilém Flusser São Paulo, 1969.

FLUSSER, Vilém. Jogos. [S. l.]: Arquivo Vilém Flusser São Paulo, 1967.

FLUSSER, Vilém. Correspondências com a Fundação Armando Álvares Penteado. [S. l.]: Arquivo Vilém Flusser São Paulo, [1966].

FLUSSER, Vilém. Correspondências com o Instituto Brasileiro de Filosofia. [S. l.]: Arquivo Vilém Flusser São Paulo, [1965].

FLUSSER, Vilém. Reflexões sobre a Traduzibilidade. [S. l.]: Arquivo Vilém Flusser São Paulo, [196-].

GEHLEN, Arnold. A alma na era da técnica: problemas de psicologia social. Lisboa: Livros do Brasil, 1960.

HEILMAIR, Alex Florian. $\mathbf{O}$ conceito de imagem técnica na comunicologia de Vilém Flusser. 2012. Dissertação (Mestrado em Comunicação e Semiótica) - Programa de Estudos Pós-Graduados em Comunicação e Semiótica, Pontifícia Universidade Católica de São Paulo, São Paulo, 2012.

KAFKA, Franz. O processo. São Paulo: Companhia de Bolso, 2017a.

KAFKA, Franz. A metamorfose. São Paulo: Companhia das Letras, 2017b.

\title{
Cultural models and the education crisis: Pedagogical paths in Vilém Flusser's Communicology
}

\begin{abstract}
The purpose of this study is to investigate the Communicology proposed by Vilém Flusser through his diagnosis of the ethical, aesthetic and epistemological changes imposed on societies. This question arises from the author's understanding that cultural models are going through a crisis, whose center is in the uncertainty about the consolidation of behaviors, experiences and knowledge, especially observed in educational structures. A little explored theme in Flusserian thought, education is understood as an ideologically planned communication for social functioning and defended as the possibility of building new knowledge, more aware and engaged in the scenarios observed by the author. In order to carry out the analysis of this
\end{abstract}


pedagogical proposition, this research carries out a bibliographic survey of these themes, put in dialogue with the other reflections of Flusser. This contextualization helps in the author's contribution in elucidating the profound contradiction that surrounds the formation of knowledge in the beginning of the 21st century, brought about by the intensification of devices that promise free global access in an environment that encourages the emerging review of learning structures.

\section{Keywords}

Vilém Flusser. Communicology. Culture and Education.

Recebido em 22/05/2020

Aceito em 09/06/2020 